\title{
Non-governmental organizations improve the social-ecological fit of institutions conserving the Andean bear in Colombia
}

\author{
$\underline{R h i a n n a ~ R . ~ H o h b e i n ~}^{1}, \underline{\text { Nathan P. Nibbelink }}^{1}$ and Robert J. Cooper $^{1}$
}

\begin{abstract}
Research has increasingly emphasized the importance of spatial alignment between ecosystems and the institutions that govern them, known as social-ecological fit. Social network analysis (SNA) has been recognized as a valuable tool capable of integrating social and ecological network data for empirical assessments of social-ecological fit. Few studies have integrated SNA with more complex spatial models, and assessments of social-ecological fit have rarely been conducted from the perspective of "fit" for wildlife conservation. We examined the spatial fit of the institutional network of heterogeneous conservation actors (both governmental and nongovernmental) working to conserve the Andean bear (Tremarctos ornatus) across the Colombian Andes. Our analysis was based upon social network and qualitative data derived from 67 semi-structured interviews with Colombian conservation practitioners along with a model of Andean bear connectivity. In Colombia, the known range of the Andean bear crosses the jurisdictional boundaries of 22 different "autonomous regional corporations" (corporaciones autonomas regionales or CARs), the primary entities responsible for implementing conservation policy in the country. We found that 53 pairs of CARs shared habitat along their jurisdictional borders that was identified as important to Andean bear connectivity, but only 16 pairs of CARs ( $30 \%$ of pairwise matches) communicated with one another about Andean bear research and conservation strategies. CARs were more likely to communicate with entities of Colombia's National Natural Park Service or with nongovernmental organizations (NGOs). These other entities were often located within the social network structure as intermediaries between otherwise disconnected CARs. These actors could use such strategic positions to facilitate coordination between CARs that share habitat important for Andean bear connectivity and, in so doing, improve social-ecological fit for the conservation of this species. Indeed, during interviews, Colombian NGOs often expressed concern over the lack of coordination among the CARs and several were working to amend the situation.
\end{abstract}

Key Words: corporaciones autonomas regionales (CAR); landscape connectivity; network governance; nongovernmental organizations; social network analysis; spectacled bear; wildlife conservation

\section{INTRODUCTION}

Research has increasingly emphasized the importance of alignment between ecosystems and the institutions that govern them. This "social-ecological fit" is proposed to be a critical facet of resilient social-ecological systems (Cumming et al. 2006, Folke et al. 2007). Without such fit, institutions may struggle to grasp the true magnitude of ecological problems they face, coordinate their actions enough to manage large-scale issues requiring collective action (Cumming et al. 2006), or address environmental externalities (Dupar and Badenoch 2002). There is a large body of literature that discusses the theoretical foundations of socialecological fit, and empirical evidence of its importance for resilient systems is accumulating. For example, Bodin et al. (2014) compared common-pool resource governance regimes in Kenya and Madagascar and found that the social-ecological system with better fit (i.e., more communication among individuals who were sharing a resource) was more sustainable and had better conservation outcomes than the system with less fit. Deteriorating ocean health has been attributed to issues with fit, specifically governance arrangements that have failed to account for links between and among managed ecosystem components (Ekstrom and Young 2009). Over time, three dimensions of socialecological fit have been distinguished: (1) temporal fit is the degree to which institutions can implement responses to ecological changes within the appropriate time frame; (2) functional fit is concerned with how well links between ecosystem components are accounted for with institutional design; and (3) spatial fit refers to the agreement between institutions and the geographical extents of ecological issues they are trying to manage (Epstein et al. 2015).

Efforts to diagnose issues of social-ecological fit abound, but the simultaneous consideration or integration of both social and ecological systems into analyses has rarely been accomplished (Pelosi et al. 2010), likely because of the incongruous nature of the two datasets. Social network analysis (SNA) is one analytical tool that has drawn increasingly more attention from scholars working to create a holistic framework for assessing socialecological fit (Sayles et al. 2019). Originally developed by sociologists in the early 20th century, SNA maps the relational or communicative ties between actors (be they individuals, agencies, or organizations) and explores how the patterns of these connections determine characteristics of the network as a whole (Scott 1988). Social networks, like all models, are by necessity an abstraction. Nevertheless, they are useful abstractions, allowing for the visualization of otherwise intangible relationships between actors, rendering visible patterns of interactions and influence (Marshall and Staeheli 2015). One of the reasons that SNA as a unifying methodology is so attractive is because networks are an analytical tool commonly found across the ecological sciences (Janssen et al. 2006, Cumming et al. 2010). Thus, SNA can be combined with various forms of ecological network data to create a powerful analysis capable of integrating and/or comparing two (or more) datasets derived from these different disciplinary perspectives. 
SNA has repeatedly proven its utility for conservation science and natural resource management (Guerrero et al. 2020). For example, SNA can be used by natural resource managers to identify ideal stakeholders for inclusion in participatory initiatives, such as actors who have connections to diverse groups and could help mediate conflicts of interest between them (Prell et al. 2009). NGOs could use SNA to target their conservation communications at "key players" who are well-positioned for disseminating new information and ideas (Mbaru and Barnes 2017) or even recruit these individuals as agents of change (de Lange et al. 2019). As traditional forms of government have been replaced by more collaborative forms of governance, SNA has become a helpful tool for informing which actors should be collaborating (Bodin et al. 2017) or identifying which organizations are performing key roles (such as bridging or brokering) in the governance network (e.g., Hahn et al. 2006, Olsson et al. 2007).

Several scholars have used SNA to diagnose social-ecological fit. For example, Pittman and Armitage (2017) used SNA and the theory of social-ecological fit to examine the ability of network governance to address ecological issues that cross terrestrial and oceanic systems in the Lesser Antilles. Pittman and Armitage (2017) showed that collaborations were more common within rather than across these two interconnected systems, concluding that social-ecological fit across "the land-sea interface" was not yet achieved by current structures of network governance. Guerrero et al. (2015) used SNA to demonstrate that a selforganized ("bottom-up") governance network was enabling some cross-scale management of ecological resources in Australia. Bergsten et al. (2014) used SNA to diagnose weak socialecological fit of a loose governance network responsible for managing a series of interconnected wetlands in Sweden and to then make recommendations about where new collaborative ties would be most beneficial for improving wetland management. These case studies have led to important insights about the relationships between different governance structures and their ability to address environmental problems. However, only a few studies thus far have integrated SNA with more complex spatial models, and we know of no study that has done so to assess the social-ecological fit of networks involved with wildlife conservation (but see Dressel et al. 2018, 2020) nor incorporated and investigated the impacts of multiple kinds of actors in such an analysis. Thus, we make novel contributions to this growing collection of informative case studies by examining the spatial fit of the institutional network of heterogeneous actors (both governmental and nongovernmental) working to conserve a flagship species, the Andean bear (Tremarctos ornatus), across the Colombian Andes.

The conservation of megafauna invariably requires the actions of numerous organizations and agencies. This is no less true in Colombia where the range of the Andean bear crosses the jurisdictional boundaries of at least 22 different autonomous regional environmental authorities (known as corporaciones autonomas regionales or CARs; see Table 1 for a glossary of acronyms) and 22 different national natural parks. Similar to other large mammals, Andean bears are thought to require large tracts of contiguous habitat (between 1200 and $1900 \mathrm{~km}^{2}$ is the most often used estimate; Yerena 1998, Peyton 1999). However, not only are most national parks in Colombia too small to support stable populations of Andean bears (Yerena 1998), many of the largest remnants of Andean cloud forest (the primary habitat of Andean bears) straddle the jurisdictional boundaries of the CARs. Given the extensive degradation to ecosystems that support Andean bears in the last half century (Kattan et al. 2004), the maintenance of landscape connectivity has become increasingly important for the species. If practitioners are only focused on the habitat within their jurisdictions, they may not readily see whether or how their seemingly smaller parcels fit within a broader context such as regional/national wildlife corridors that are critical to this species' long-term survival. The CARs have no mandate to coordinate their efforts with one another, not even among those neighbors that share jurisdictional boundaries. However, self-organized networks of actors that collaborate to address common challenges are documented in a variety of different landscapes and have been shown to improve social-ecological fit (Guerrero et al. 2015, Sayles and Baggio 2017). In previous work, we documented that knowledge of border-crossing Andean bears had spurred some voluntary inter-institutional coordination among CARs (Hohbein et al. 2021), but the extent to which these collaborations correspond to Andean bear connectivity has not yet been explored.

Table 1. Glossary of acronyms.

\begin{tabular}{ll}
\hline \hline Acronym & Meaning \\
\hline CAR & $\begin{array}{l}\text { Corporaciones Autónomas Regionales, Autonomous } \\
\text { Regional Corporation }\end{array}$ \\
HCH & $\begin{array}{l}\text { Highly connective habitat } \\
\text { Ministerio de Medio Ambiente y Desarrollo } \\
\text { MinAmbiente }\end{array}$ \\
& $\begin{array}{l}\text { Sostenible, Ministry of the Environment and } \\
\text { Sustainable Development }\end{array}$ \\
NGO & $\begin{array}{l}\text { Nongovernmental organization } \\
\text { PNN }\end{array}$ \\
SNA & $\begin{array}{l}\text { Service Nacionales Naturales, National Natural Park } \\
\text { WCI }\end{array}$ \\
\hline
\end{tabular}

The vast majority of preceding research on the spatial fit of institutions has concentrated on spatially bound organizations operating within distinct and readily identifiable jurisdictions (e.g., Bergsten et al. 2014, Alexander et al. 2017, Enqvist et al. 2020). We wish to expand upon this literature by integrating "non-jurisdictional" actors into our analysis and explicitly examining the impacts these actors have on indices of spatial fit. In our study system, these non-jurisdictional actors are nongovernmental organizations (NGOs) that work to conserve Andean bears in collaboration with or independently from the efforts of the CARs and the Colombian National Natural Park Service (Parques Nacionales Naturales [PNN]). These actors may serve particularly important roles in environmental governance because they are not bound to distinct jurisdictions and thus may serve as intermediaries among those that are spatially bound. If NGOs are serving in this capacity, they would improve the potential for knowledge diffusion and collective action in the governance network (Bodin and Crona 2009) as well as increase the likelihood that disconnected organizations would communicate in time, because of their mutual correspondent(s) and the principle of triadic closure-simply 
put, the propensity for two "friends" of a third friend to eventually become friends themselves (Pittman and Armitage 2017). Orejuela and Jorgenson (1999) had even anticipated that NGOs would play an important role in coordinating Andean bear management efforts in the then-newly decentralized environmental system of Colombia (the new system had included legislation which provisioned for greater NGO involvement in environmental governance). By including these actors in our analysis, a more complete and nuanced understanding of social-ecological fit in this system can be gained.

We draw on the theories of social-ecological fit, landscape connectivity, and social network analysis to examine the following research question: How does the structure of the institutional network across the Andean mountains impact its collective ability to conserve a flagship species, the Andean bear? We had three overarching objectives guiding this research: (1) To assess socialecological fit of the current governance structure in Colombia for the conservation of the Andean bear; (2) to determine the impacts non-jurisdictional organizations have on the network and indices of social-ecological fit; and (3) to identify opportunities for strategic "network weaving" that could strengthen the conservation network and improve social-ecological fit. This research is informed by qualitative and social network data derived from 67 interviews with 71 different conservation practitioners in Colombia, as well as a model of landscape connectivity across the Colombian Andes constructed with circuit theory (Hohbein and Nibbelink 2021).

\section{METHODS}

\section{Study system}

\section{Environmental governance}

In Colombia, the shift from centralized power and decisionmaking authority to that which is decentralized and vested in these CARs is a relatively recent one. One of the purported advantages of this shift toward decentralized governance was, though not explicitly put in these terms, to improve socialecological fit of environmental governance in the country. The previous national environmental authority, INDERENA, had been unable to adequately respond to and address regional issues of environmental degradation. They lacked the ability to be present in regions far-flung from the capital, they did not have the necessary local-scale knowledge, and, in short, the feedback loops between local problems and national level decision making were broken (Rodríguez Becerra 2009). Partly in response to international pressure and partly in response to social and political turmoil within the country, Colombia adopted political decentralization in 1991 (Pening Gaviria 2003). Two years later, natural resource management was also decentralized with Law 99 of 1993 and the creation of 33 CARs whose jurisdictions now covered the entirety of the country. INDERENA was restructured into what is today the Ministry of the Environment and Sustainable Development (Ministerio de Ambiente $y$ Desarrollo Sostenible [MinAmbiente]).

The MinAmbiente creates national environmental policy, and the CARs are the entities responsible for implementing it within their jurisdictions, albeit with substantial room for discretion (Blackman et al. 2004). In addition to their primary responsibilities of managing natural resources, the CARs are also expected to work for the conservation of threatened and endangered species such as the Andean bear. National natural parks and the biodiversity within are managed separately from the CARs by Colombia's National Natural Park Service (Parques Nacionales Naturales [PNN]; there are also regional natural parks that are designated and managed by the CARs). PNN has an administrative hierarchy tiered at the national, regional, and local (park) level. Though the MinAmbiente was originally intended to lead the collective environmental governance system in Colombia and facilitate coordination among the CARs, previous research has documented that they have not fully fulfilled this responsibility (Blackman et al. 2004, Hohbein et al. 2021).

In addition to the CARs, PNN, and the MinAmbiente, there are many environmental NGOs working at various scales across Colombia. When Colombia restructured its environmental governance, NGOs were clearly expected to become key actors in natural resource management. NGOs were formally integrated into the National Environmental System (Law 99 of 1993, Article 4); it was envisioned that they would help the state perform some of its functions in environmental governance (Law 99 of 1993, Article 1). Law 99 requires that the board of directors of each CAR includes two representatives from the civil society sector and encourages research institutes to partner with environmental NGOs to accomplish their objectives. Today, many Colombian NGOs are contractors, conducting research or implementing projects that staff at CARs do not have either the time, expertise, or manpower to do themselves. NGOs also often partnered with PNN; PNN entities are unable to accept economic resources directly and so require third-party executors to manage funds meant to benefit PNN projects or programs. International NGOs often have superior access to financial resources than their Colombian counterparts and can leverage these resources to build long-term programs for conservation or initiate partnerships with CARs and PNN, occasionally subcontracting components of this work to Colombian NGOs.

\section{Colombian Andes}

The Colombian Andes comprise three mountain ranges or cordilleras that extend from the southwestern to the northeastern borders of the country. The Andean region in Colombia covers approximately $285,000 \mathrm{~km}^{2}$, roughly one-fourth of Colombia's total surface area. The Colombian Andes are considered to be a global biodiversity hotspot (Mittermeier et al. 1999). The Colombian Andes are also the center of the country's economic activity. Close to $70 \%$ of Colombia's 50 million residents currently reside in the Andean region. Andean ecosystems in Colombia have been inhabited for millennia (van der Hammen 1992, as cited in Etter et al. 2008), but the most drastic changes to these ecosystems occurred after Spain's colonization of the country in the 1500 s and the subsequent introduction and proliferation of cattle ranching (Etter and van Wyngaarden 2000). Indeed, cattle ranching continues to be a "dominant land use and driver of landscape change" in the Colombian Andes (Etter et al. 2008:12). Other prominent factors in land cover change during the 20th century were illicit drug cultivation, particularly for cocaine (Mantilla Valbuena 2012) and Colombia's adoption of neoliberal economic policies that prioritized natural resource extraction (Vélez-Torres and Ruiz-Torres 2015, Gutiérrez-Gómez 2017). In the latter half of the 20th century, Colombia also experienced exponential population growth and substantial rural-to-urban 
migration, which have had important implications for Andean ecosystems (Etter et al. 2008). Rural-to-urban migration has allowed for some forest recovery, but the end of Colombia's 50year civil war and promises of rural reform may soon reverse these trends (Negret et al. 2017). Approximately 16\% of the Andean region in Colombia is under some form of protection (Bax and Francesconi 2019).

\section{Andean bears}

Andean bears (also known as spectacled bears, in Spanish osos de anteojos or osos andinos) are the only bear species in South America and the last surviving lineage of the subfamily Tremarctinae (García-Rangel 2012). Andean bears are a relatively under-studied species (Falconi et al. 2020), especially among charismatic megafauna. However, evidence has been accumulating that the species has experienced population declines over the last several decades; the International Union for the Conservation of Nature classifies Andean bears as vulnerable to extinction (Velez-Liendo and García-Rangel 2017). Rough estimates place the current number of Andean bears between 13,000 and 18,000 individuals across the five countries where they occur: Bolivia, Peru, Ecuador, Venezuela, and Colombia (VelezLiendo and García-Rangel 2017). However, some regard these estimates with skepticism; there may be far fewer Andean bears than this (Peyton et al. 1998, Garshelis 2011). Andean bears primarily occupy high elevational zones (above $1200 \mathrm{~m}$ ) in cloud forest and shrub ecosystems known as páramo.

Andean bears have experienced substantial habitat loss across their range, much of this loss occurring in only the last half century because of increasing agricultural conversion and upslope development from populous inter-mountain valleys (Etter et al. 2008). Previously, governments had relied on the simple inaccessibility of cloud forest as a de facto approach to Andean bear habitat protection (Peyton 1999). However, increased transportation infrastructure across the Andes has severely lessened the efficacy of this approach (Peyton 1999) and compromised the integrity of these previously intact forests. Andean ecosystems are recognized to be extremely fragmented (e.g., Armenteras et al. 2003), which has important implications for the persistence of this large-bodied species. Fragmentation in the Andes implies the loss of landscape connectivity for Andean bears as well as other species occupying these habitats; landscape connectivity is important for the maintenance of metapopulations, natal dispersal, mating opportunities, and nutritional requirements (Taylor et al. 1993). Furthermore, landscape connectivity may be essential for climate change adaptation by allowing montane species to adjust their home ranges in response to shifting climate envelopes (Davis and Shaw 2001, Littlefield et al. 2019). Though many CARs have established regional protected areas to prevent further degradation of core Andean bear habitat, the explicit consideration of cross-jurisdictional connectivity in the selection of these areas would improve the net benefits achieved for Andean bear persistence in the landscape.

The second greatest threat to Andean bears is poaching. Although poaching in other countries is often driven by the illegal trade in wildlife parts, poaching in Colombia is more commonly tied to issues of human-bear conflict (Peyton 1999). Andean bears are largely herbivorous and can cause tremendous damage to crops (Peyton 1980). They also scavenge, a behavior that has implicated them in livestock losses across the Andes (Goldstein et al. 2006).
Further, there has been increasing evidence that some "problem" Andean bears will attack and kill livestock (Zukowski and Ormsby 2016, Parra-Romero et al. 2019), something that Andean ranchers have suspected and/or witnessed but whose perspectives, until recently, have been met with skepticism from many conservation practitioners (Hohbein et al. 2021). Issues with human-bear conflict are further exacerbated at the jurisdictional boundaries between CARs, as ambiguous responsibilities occasionally lead to calls from locals for institutional intervention in Andean bear depredation events to go unanswered; frustrated ranchers may then take matters into their own hands (Hohbein et al. 2021).

\section{Network analysis framework, briefly}

Social networks comprise nodes (sometimes called vertices) connected by ties (sometimes called edges). Nodes represent actors in the network while the ties that connect them represent some form of relationship, be it friendship, communication, or formal agreements. In our network analysis, the nodes represent conservation actors across the Colombian Andes, specifically the CARs, PNN, and NGOs (Fig. 1). We distinguish two types of possible ties: ecological ties (defined by probable Andean bear movement between the jurisdictions of the CARs, elaborated below) and institutional ties (representing communication, collaboration, contracts, or other forms of institutional exchanges). Ties involving PNN or NGOs are institutional, whereas ties between CARs could be either institutional or ecological.

Fig. 1. An example of a social network. Note the vast amount of information that can be portrayed; e.g., in this example, the ties between actors are of varying widths, indicating differing strengths of connections. The nodes themselves are sized according to the number of connections held by each; the middle autonomous regional corporation (corporaciones autonomas regionales [CAR]) has four connections, the most in the network, and so is depicted with the largest circle (but sizes can also be indicative of other social network metrics). Nodes can also be color-coded to indicate different kinds of actors, as above, where green represents entities of Parques Nacionales Naturales (PNN), blue represents nongovernmental organizations (NGOs), and black represents the CARs.

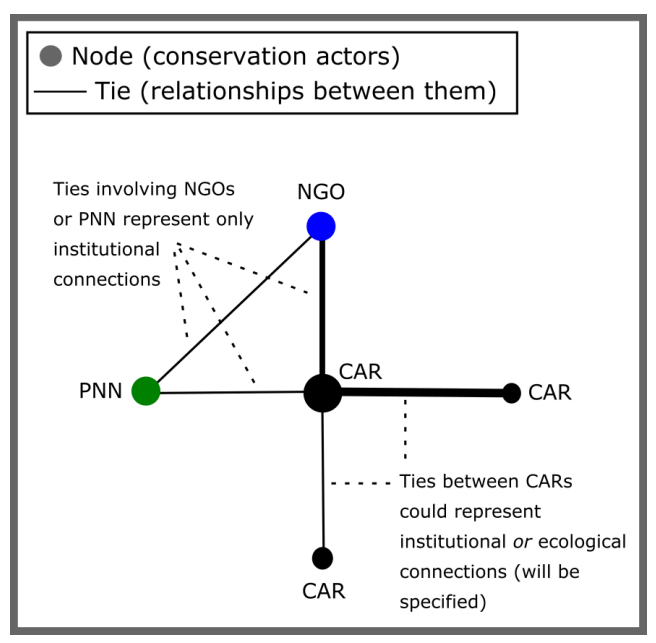




\section{Mapping the ecological network}

We used a model of omnidirectional connectivity for Andean bears (Hohbein and Nibbelink 2021) as the basis for the ecological network across the Colombian Andes. Connectivity models help delineate those areas in the landscape that are most conducive to movement of the focal species for which they are developed. We produced this circuit-based model largely following the methodology of Koen et al. (2014). Briefly, circuit-based models of landscape connectivity draw parallels between electrical current and animal movement (McRae et al. 2008). These models assume organisms have no prior knowledge of the landscape and thus move as predicted by correlated random-walk theory (McRae et al. 2008). Areas shown to have higher levels of "current" in the circuit-based models are predicted to have higher use by animals engaged in correlated random walks. These models are guided by resistance values set by the spatial analyst that correspond to the degree to which different landscape features are understood to hinder or enable movement, e.g., high-volume highways usually have high resistance values because they are thought to be quite difficult for organisms to cross.

We used this connectivity model to quantify the degree to which neighboring CARs were ecologically connected via the probable movement of Andean bears given the distribution of habitat considered to be important for Andean bear connectivity, i.e., those areas in the model with high current. Several steps were required to turn this current map into an ecological network. First, we categorized into 5 classes the distribution of current values across the Colombian Andes according to Jenks natural breaks (Jenks 1967). Those areas that had current values that fell into the highest two classes were categorized as highly connective habitat (HCH; Fig. 2). We then calculated the total amount of $\mathrm{HCH}$ (in terms of $1-\mathrm{km}^{2}$ pixels), which was intersected by pairwise jurisdictional boundaries between CARs. Those that had $0 \mathrm{~km}^{2}$ of shared $\mathrm{HCH}$ were considered ecologically disconnected in our analysis, i.e., they did not share ecological ties. We then calculated the quartile values of counts of shared cells of $\mathrm{HCH}$ (excluding 0 values). These quartiles guided the strength of ecological ties assigned to pairwise CARs. Neighbors that shared $\mathrm{HCH}$ cell quantities in the highest quartile were assigned an ecological tie with a strength of 3 ; those in the middle two quartiles were assigned moderately strong ecological ties (2); while those in the lowest quartile were assigned ecological ties with a strength of 1 .

\section{Mapping the institutional network}

Semi-structured interviews

R. Hohbein (RH) traveled to Colombia between August 2018 and September 2019 to conduct 67 semi-structured interviews (Bernard 2011) with 71 different conservation practitioners. These individuals included the representatives of 22 CARs and 20 nongovernmental organizations, as well as 12 PNN employees. Interviews were conducted in person whenever possible; interviews were conducted over telephone/video chat when inperson interviews were not possible. All interviews but one were audio-recorded and only after receiving verbal consent from interview participants. The majority of the interviews were conducted in Spanish with the assistance of one of three local translators. RH was always present as the primary interviewer. The Institutional Review Board at the University of Georgia approved all research conducted for this study (Protocol ID
\#STUDY00005270). No Colombian permits were required for this research.

Fig. 2. This connectivity model for Andean bears in Colombia was constructed with circuit theory and was the basis for the ecological network in this analysis. Areas in green are those that were predicted by the model to be most important for Andean bear (Tremarctos ornatus) connectivity within the delineated study area (blue). Jurisdictions of the autonomous regional corporations (corporaciones autonomas regionales [CARs]) are depicted.

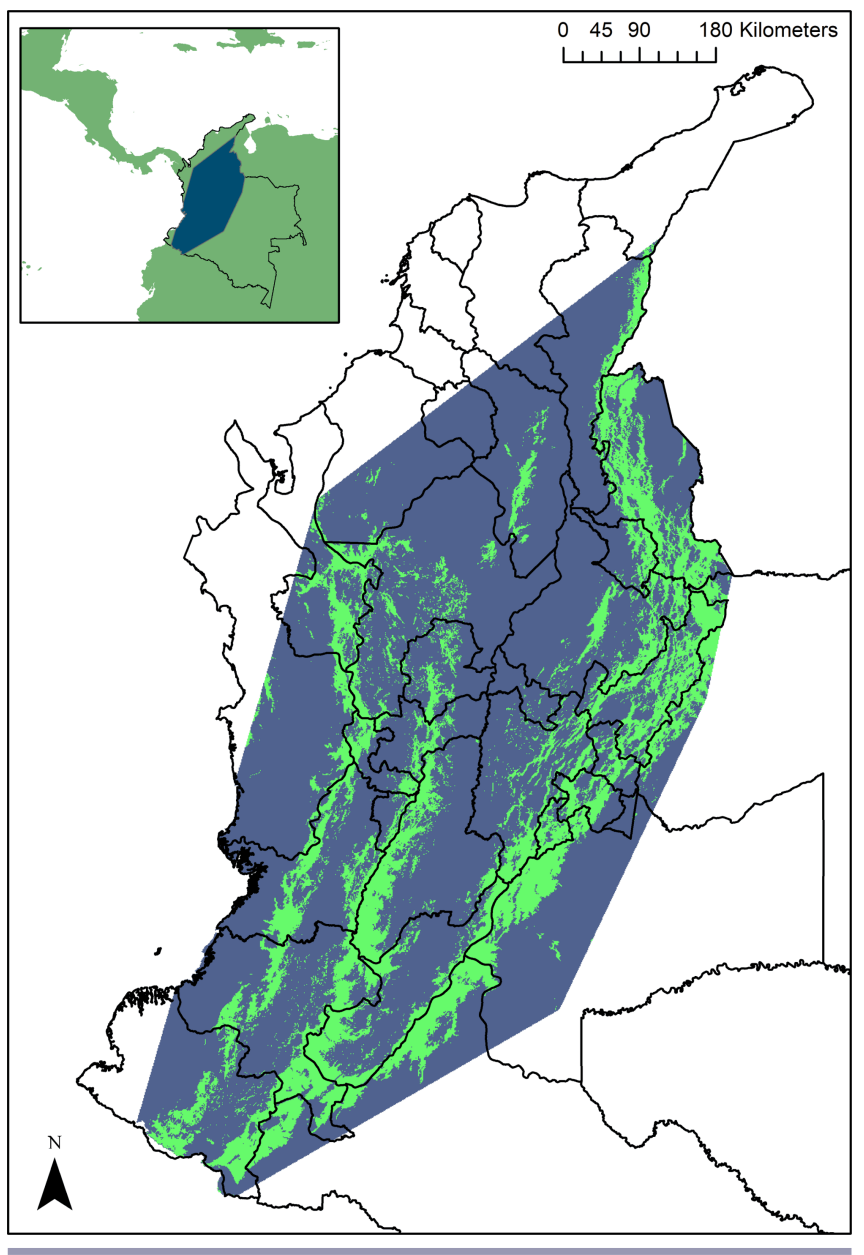

We asked interview participants (1) to free list all entities with whom they either collaborated, contracted, or otherwise discussed Andean bear conservation or research and (2) to describe the frequency and nature of their communication with those identified. These various relationships collectively comprised the institutional network. We also asked participants (3) to elaborate on challenges in these relationships, benefits to these communication ties, and overall observed barriers to collaborative efforts in the country. We did not include institutional ties that covered topics other than Andean bear conservation and research activities, nor did we include ties to actors that were not one of the three types of actors we were investigating (NGOs, CARs, and PNN). In addition to these network-centric questions, we asked participants to describe 
Andean bear conservation and research strategies implemented by their institutions, the challenges experienced while implementing these efforts, and primary threats to the species within their jurisdictions (if applicable).

\section{Interview sampling strategy}

We contacted all 26 CARs across the Colombian Andes. We interviewed at least one representative from all CARs with coincident Andean bear habitat and confirmed or suspected Andean bear presence $(n=22)$. RH interviewed representatives from all six territorial directorates (the regional tiers) of PNN and two representatives working at the national level. Park-level employees were interviewed only opportunistically. We began NGO interviews with the Wildlife Conservation Society Colombia (WCS) and Fundación Wii. We then used chain referral sampling, i.e., snowball sampling, to identify other NGOs or nonprofits who were involved with Andean bear conservation. We did not follow up for interviews with NGOs named during chain referral sampling if the NGOs identified were not actively involved with creating, implementing, or managing projects that directly dealt with Andean bears. See Hohbein et al. (2021) for a full description of the interview sampling strategy.

\section{Strength of ties}

We assigned all institutional ties strengths of either 1,2 , or 3 according to various qualifications (see Table 2). If respondents indicated different strengths for a mutual tie, we used the higher value. Representatives from four CARs in the Andes communicated that they had no evidence of Andean bear presence in their territories and thus were not engaged in any conservation activities specific to the species; we assumed they had no communication ties with other entities specific to Andean bears.

Table 2. Characteristics of the different strengths assigned to institutional ties between actors

\begin{tabular}{|c|c|}
\hline Strength & Qualifications \\
\hline 1 - Weak & $\begin{array}{l}\text { "communication explicitly described as "weak" or very } \\
\text { infrequent } \\
\text { •other indicators of weak communication (e.g., } \\
\text { participation in multi-party agreement described as } \\
\text { "non-active") } \\
\text { "previous collaboration or contract between parties, but } \\
\text { no indication provided of ongoing communication } \\
\text { relationships described by one or both parties as } \\
\text { "tenuous" or "challenging," but that still included some } \\
\text { component of information exchange }\end{array}$ \\
\hline 2 - Moderate & $\begin{array}{l}\text {-grants or funds provided, but no collaborative effort } \\
\text { apparent } \\
\text { "contracts provided (similar to above); not considered } \\
\text { "partners" } \\
\text { •all other relationships not scored as } 1 \text { or } 3\end{array}$ \\
\hline 3 - Strong & $\begin{array}{l}\text { "communication explicitly described as "strong" or } \\
\text { "constant" }\end{array}$ \\
\hline 3 - Strong & $\begin{array}{l}\text {-partners that shared or were active members of a signed, } \\
\text { formal agreement for collaborative work }\end{array}$ \\
\hline
\end{tabular}

\section{PNN specificities}

For ease of analysis, we collapsed ties to individual national natural parks to the territorial directorate within which the parks belonged. For example, if a CAR or NGO described an information exchange or collaboration with Chingaza National Natural Park, we considered this to be a tie to the PNN territorial directorate of Orinoquía. We assumed all territorial directorates had a moderate tie to the PNN National Administration unless respondents from the territorial directorates indicated otherwise (as per Table 2). Communication among territorial directorates was only included if it was mentioned by interview respondents. However, we did not explicitly ask about communication between territorial directorates and thus these inter-territorial ties may be underrepresented.

\section{Workflow for analyzing the social-ecological fit among CARs}

We first compared the ecological network and institutional network among the CARs exclusive of the other two types of conservation actors, i.e., PNN and NGOs. Specifically, we tested the frequency with which the strengths of communications between neighboring CARs corresponded to the degree to which they were ecologically connected via Andean bear movements. From the perspective of spatial fit, the "ideal" outcome of this analysis would be a perfect match between the institutional and ecological networks. Our analysis thus reveals the extent to which this ideal scenario was realized at the time of our research and highlights the degree of disparity between these two metrics among neighboring CARs. We assessed fit only among neighboring CARs unless non-neighboring CARs indicated shared institutional ties, in which case these data were included. Andean bear populations potentially cross multiple CARs and are thus possibly shared among CARs that are not adjacent to one another. We chose not to include these more complex dynamics in our analysis of social-ecological fit for it would have required us to make more problematic assumptions about the structure of Andean bear populations and movements. The level of analysis presented here is a valuable first assessment because it highlights those places where new institutional ties between CARs would be most imminently beneficial for enhancing the fit of Andean bear conservation.

We then integrated into our social-network analysis the entities of PNN and relevant NGOs. We trimmed NGOs from this network who held only one tie to other actors in our network. The networks of local-scale NGOs are thus not well-represented in this analysis because their communications likely included (1) only one CAR (within whose jurisdiction they are located), (2) park-level employees (who were not systematically interviewed), and/or (3) other local-scale NGOs. All CARs and PNN entities were included regardless of the number of ties held. For this complex network, we calculated standard SNA metrics including degree centrality, betweenness centrality, and eigenvector centrality (see Table 3 for definitions of these metrics). Additionally, we assessed the number of connected components and examined the shortest paths between all neighboring CARs that did not share direct institutional ties. These analyses give us insights into the impacts these different kinds of actors had on the conservation network across the Colombian Andes.

Finally, we calculated an index of connectedness among neighboring CARs, which theoretically corresponds to the degree to which information from one CAR would likely reach another. This weighted connectedness index (WCI) is derived from the 
number of unique pathways connecting the two CARs divided by (1) the length of the shortest pathway between the two CARs, i.e., the number of intervening nodes, and then by (2) the cumulative weight of the shortest pathway between the two CARs. The weight is the reversed rank order of the strengths of the intervening ties (i.e., strength of $1=$ weight of $3 ; 2=2 ; 3=1$ ) and indicates increasing difficulty for information passage. We compared the relative contributions of PNN entities and NGOs on WCIs between CARs that were not directly communicating with one another with an analysis of variance (ANOVA) in Program R. We followed this with a post-hoc Tukey's honestly significant difference to determine which type of actor's inclusion resulted in significant differences to WCIs.

Table 3. Definitions of common social network analysis metrics

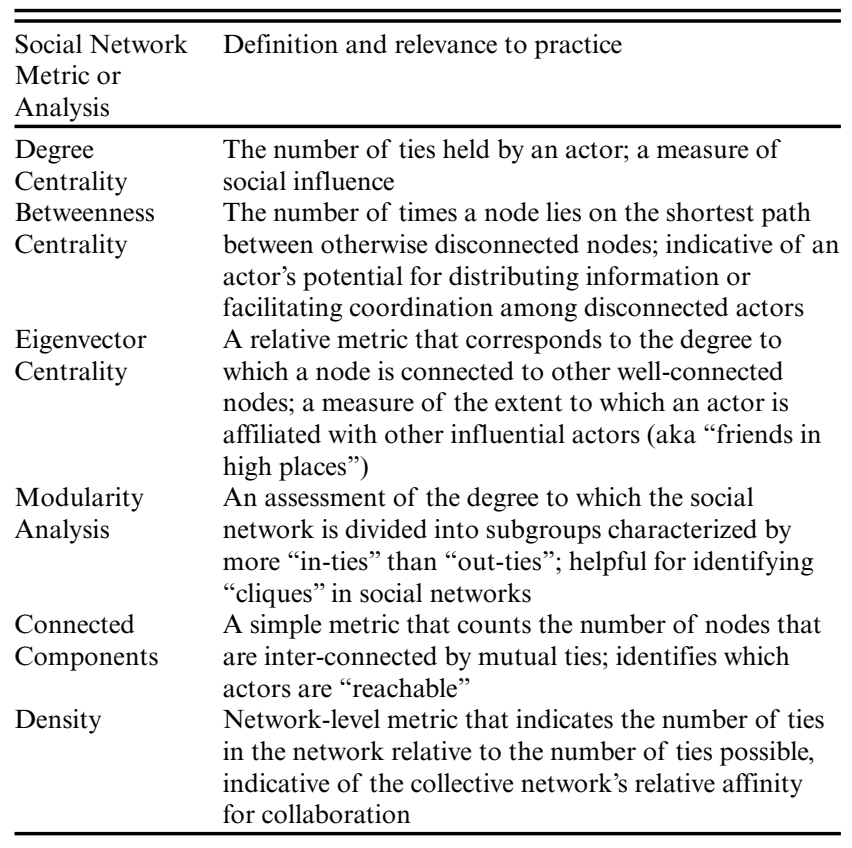

We conducted most SNA analyses in Gephi Graph Visualization and Manipulation software (v. 0.9.2). We used Program R to identify the shortest paths between the CARs. All statistics were performed in Program R.

\section{Qualitative analysis}

Although SNA can reveal many important insights about socialecological fit, the analysis is more meaningful when qualitative data is considered as well (e.g., Riggs et al. 2020). Bodin (2017) describes the important insights possible through a deeper understanding of the actors in the network such as their motivations, objectives, and even personal characteristics. These insights can reveal whether central actors are playing positive roles (leading, connecting), neutral, or negative roles (withholding information). In other words, qualitative data provide an opportunity to assess the meaning of interactions, insights that cannot be gathered by an analytical analysis of network structure alone (Fuhse and Mützel 2011). Transcripts of the 67 semistructured interviews were translated into English and then imported in MaxQDA (VERBI Software 2017) for analysis. We used an iterative coding process to identify emergent themes
(Saldaña 2016). Following the more traditional format of the social sciences, we incorporate our qualitative data into our discussion to contextualize results.

\section{RESULTS}

\section{Ecological network among CARs}

Sixty-seven pairs of CARs shared jurisdictional boundaries in the Colombian Andes. Of these pairs, 53 shared habitat important to Andean bear connectivity. Thus, if CARs were neighbors, there was $79.1 \%$ chance that they shared at least some amount of habitat critical to Andean bear connectivity $(\mathrm{HCH})$ (range: $2-378 \mathrm{~km}^{2}$; $\mathrm{M}=85.4 \mathrm{~km}^{2}$ ). Each CAR shared $\mathrm{HCH}$ with an average of 4.08 neighbors (range: 1-8). Modularity analysis detected four interconnected "ecoregions" across the Colombian Andes (Fig 3 ). We refer to these ecoregions later in our analysis to characterize conclusions about the relative fit of institutions in different parts of the Andes.

Fig. 3. Ecological network across the Colombian Andes based upon probable Andean bear (Tremarctos ornatus) movement given the distribution of habitat critical to Andean bear connectivity across jurisdictional boundaries. Jurisdictions of each of the autonomous regional corporations (corporaciones autonomas regionales [CARs]) are delineated; each CAR is represented by a circle. CARs that shared habitat critical to Andean bear connectivity are connected by lines; increasing line width is associated with more shared habitat and thus a stronger ecological connection in the network. Node sizes are indicative of relative ecological degree centrality of each CAR. Colors are indicative of four "ecoregions" detected with modularity analysis.

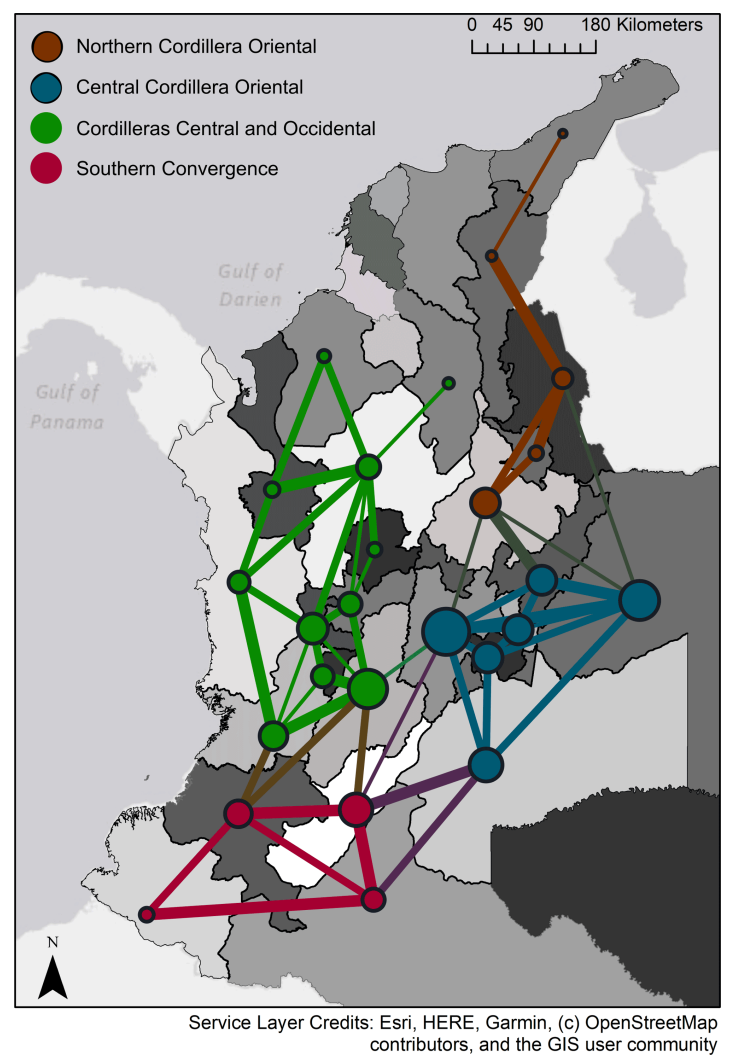




\section{Institutional network among CARs}

Very few CARs listed other CARs among those with whom they collaborated, coordinated, or shared data with respect to Andean bear conservation or research (also reported in Hohbein et al. 2021). Overall, 23 pairs of CARs (consisting of 14 unique CARs) shared social ties regarding Andean bear conservation and research efforts, providing a network density score 0.071 ; i.e., of all possible pairwise connections between CARs $(n=325), 7.1 \%$ were realized (Fig. 4). Most of these connections ( $n=15,65.2 \%$ ) came from a regional collaborative agreement among CARs in the central portion of the eastern cordillera of the Andes. Seven of the remaining eight connections among CARs were weak ties that represented isolated conversations. Each CAR had communicated to an average of 1.77 other CARs about Andean bear conservation or research efforts.

Fig. 4. Institutional network among the autonomous regional corporations (corporaciones autonomas regionales [CARs]) regarding Andean bear (Tremarctos ornatus) conservation and research. CARs that are connected by lines had shared some level of communication, coordination, or collaboration; thicker lines are indicative of "stronger" ties between the CARs.

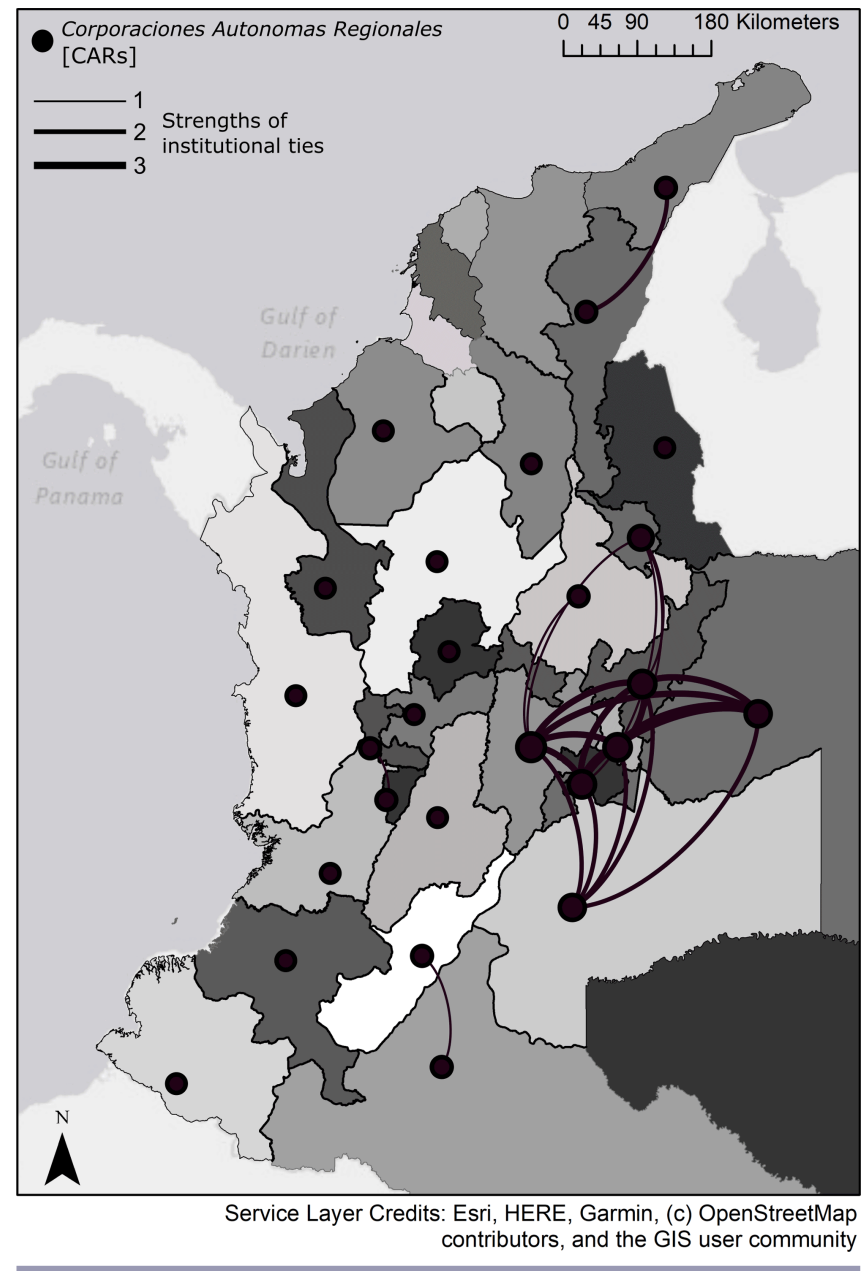

Social-ecological fit of the CARs

Of the 53 pairs of CARs that shared $\mathrm{HCH}$, only 16 communicated with one another; the other 37 did not communicate on the subject of Andean bears. Of the 13 pairs of CARs we classified as sharing the highest level of ecological connectivity $\left(104-378 \mathrm{~km}^{2}\right.$ of $\mathrm{HCH})$, only three communicated $(23.1 \%)$. Two pairs had strong social ties (strength of 3 ), while the third had a weak social tie (strength of 1). This indicates that 10 pairs of CARs were missing critical social ties, i.e., had the highest degree of social-ecological mismatch. Of the 26 pairs of CARs we classified as sharing a moderate amount of ecological connectivity $\left(28-104 \mathrm{~km}^{2}\right.$ of $\mathrm{HCH})$, nine communicated $(34.6 \%)$. Five of these pairs had strong social ties, three had moderate social ties, while one had a weak social tie. Figure 5 is a representation of the degree of socialecological fit among the CARs across the Colombian Andes given the degree of agreement between the ranking of the ecological tie and the weight of the social tie; those with the strongest ecological connection but that did not communicate resulted in the greatest social-ecological mismatch. The central portion of the eastern cordillera had the best fit of the four ecoregions.

Fig. 5. Social-ecological fit of the autonomous regional corporations (corporaciones autonomas regionales [CARs]) with respect to Andean bear (Tremarctos ornatus) conservation and research across the Colombian Andes. Social-ecological matches and mismatches are premised on the degree of alignment between the strengths of institutional and ecological ties between the CARs. Nodes are sized by ecological degree centrality.

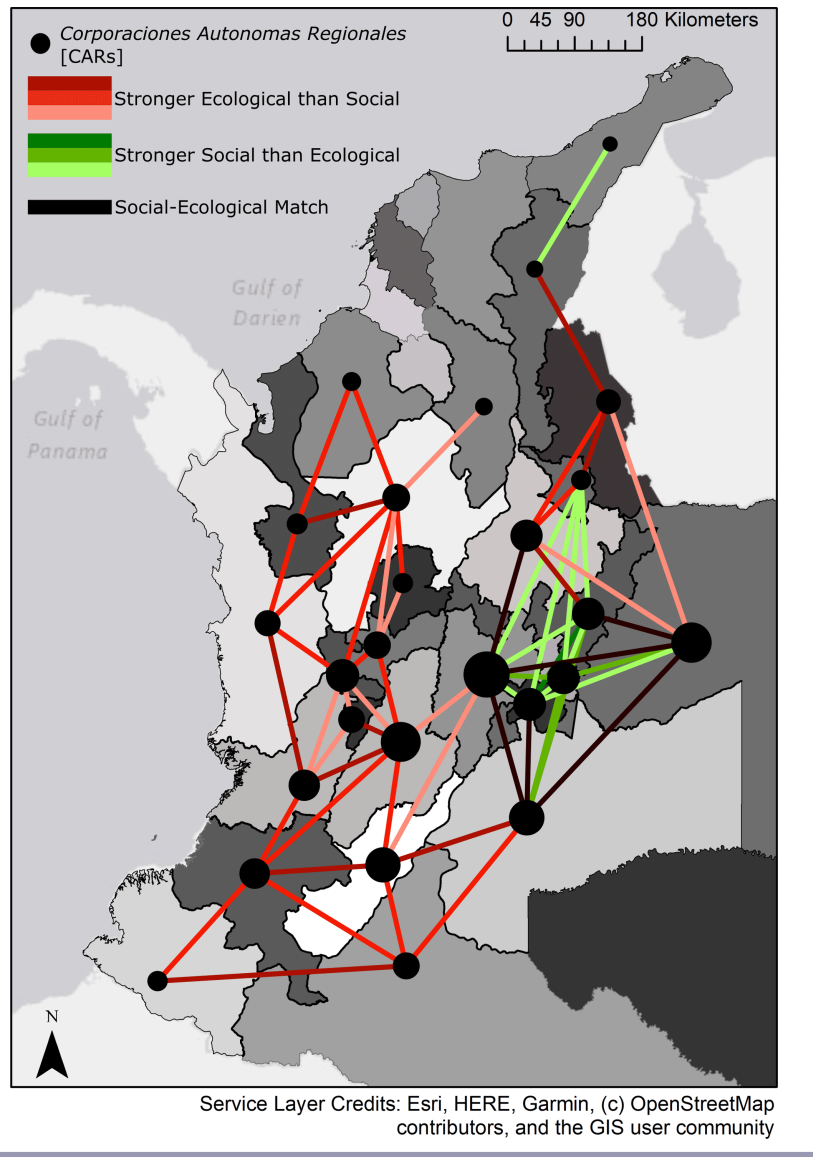


Fig. 6. Complex social network among the autonomous regional corporations (corporaciones autonomas regionales [CARs]; black nodes), entities of Colombia's National Natural Park Service (green), and nongovernmental organizations (blue). Thicker lines are indicative of stronger institutional ties regarding Andean bear (Tremarctos ornatus) conservation and research. Node size is indicative of relative degree centrality of each organization in the network.

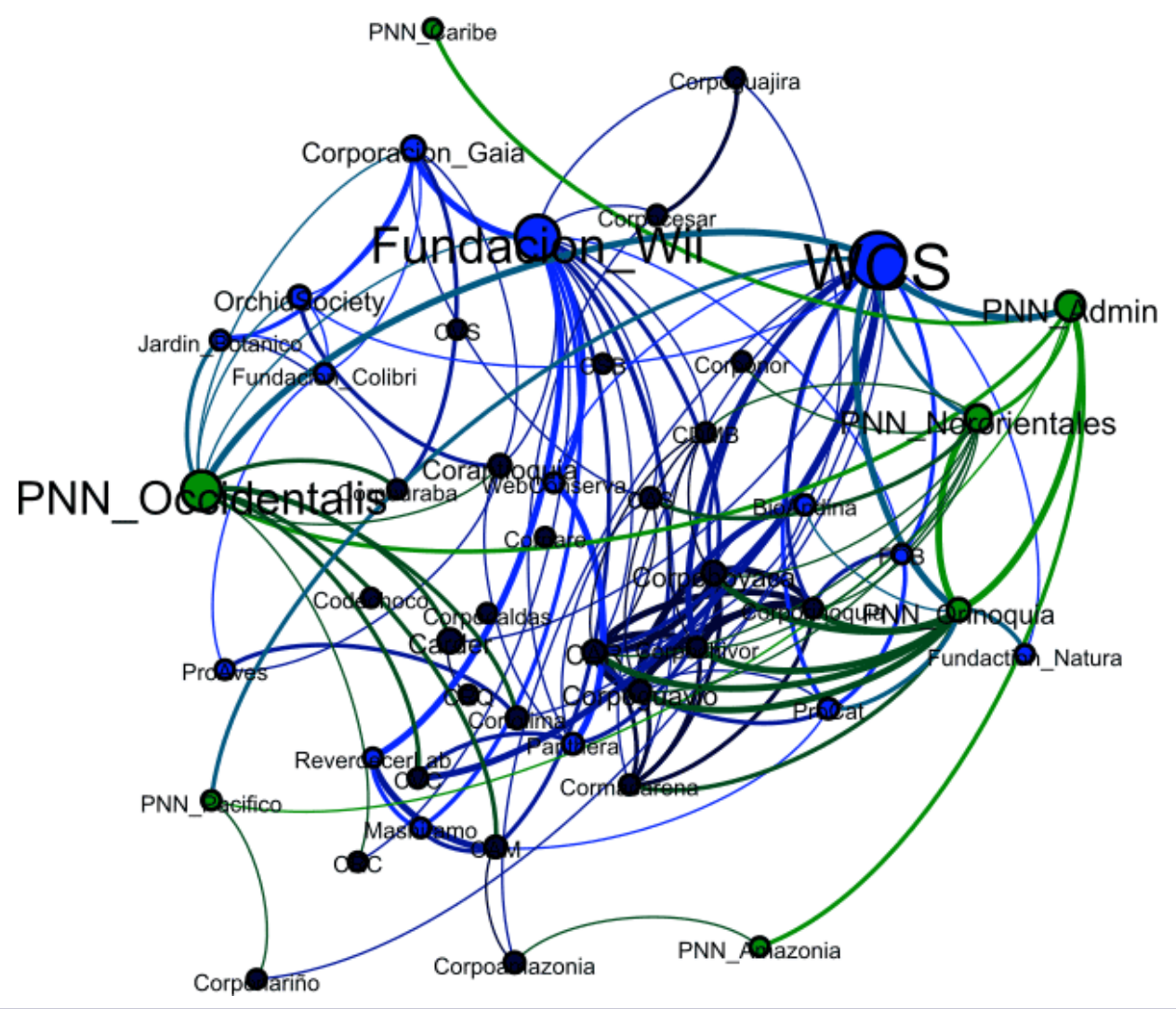

\section{Complex social network among CARs, PNN, and NGOs}

Many CARs identified PNN as an organization with whom they collaborated on Andean bear conservation or exchanged information on the topic ( $\mathrm{n}=18 \mathrm{CARs}$; 0.881 ties to PNN per CAR); collaborations and information exchanges with NGOs were even more common $(\mathrm{n}=19$ CARs; 1.651 ties to NGOs per CAR; Fig. 6). The inclusion of these other types of actors increased the average degree centrality of CARs to 4.31 ties. NGOs had an average degree centrality of 6.33 ties relevant to Andean bear conservation and research, whereas PNN entities had an average degree centrality of seven ties. Of the three types of actors, PNN entities had, on average, the highest betweenness centrality scores (48.01), followed closely by NGOs (40.16), whereas CARs had the lowest average betweenness centrality scores (9.52). The two entities with the highest betweenness centralities in the complete network were both NGOs (WCS and Fundación Wii); notably, these two NGOs did not communicate with one another. WCS had the highest eigenvector centrality score in the network, followed by members of the interinstitutional agreement of the eastern cordillera, including participating PNN territorial directorate Orinoquía and closely aligned territorial directorate Nororientales.
The inclusion of these other types of actors of natural resource governance into the social-network analysis improved many metrics of network cohesion. Because of the higher number of ties held by PNN entities and NGOs, the graph density increased from 0.071 (with only the CARs) to 0.113 (i.e., $11.3 \%$ of all possible ties were realized). Another metric that relates to cohesion is the number of connected components. In the previous analysis that considered only the CARs, most appeared disconnected from any network, i.e., they were "isolates". The inclusion of ties to other types of actors greatly changed the number of CARs that were within connected components. The inclusion of ties to PNN resulted in two groups of connected CARs: one group contained 19 CARs that were at least weakly connected to one another through mutual correspondents; the other contained two connected CARs. The remaining five CARs remained isolated. The inclusion of ties to NGOs resulted in similar changes to the network: there were 20 CARs that were at least weakly connected through mutual correspondents, while six CARs again remained isolated. When all three types of actors were included (CARs + PNN + NGOs), 21 CARs were within a single connected component, while five remained isolates. 
The integration of these other two types of actors into the SNA revealed that 25 pairs of $\mathrm{CARs}$ that shared $\mathrm{HCH}$, and had appeared disconnected from one another, were connected via mutual correspondent(s); the paths among these CARs had an average cumulative weight of 5.4 (Fig. 7). PNN entities were on the shortest paths between 19 pairs of previously disconnected CARs that shared $\mathrm{HCH}$, whereas NGOs were between nine pairs. To better understand the differential effects these two different types of actors had on the social network, we assessed their unique contributions in isolation from the other on our index of connectedness (WCI); i.e., we assessed the connectedness index on a network with only CARs and PNN and then again with CARs and NGOs. We found that the removal of NGOs from the network resulted in a significant decrease to the WCI between disconnected CARs $(61.8 \%, \mathrm{p}<0.01)$, whereas the removal of PNN resulted in a less dramatic reduction to the WCI among those CARs (42.8\%, not significant, $\mathrm{p}>0.05)$. This difference between the average WCIs was not due to NGOs significantly shortening the paths between disconnected CARs, but rather because their inclusion in the network introduced alternative pathways through which information could travel between the CARs.

\section{DISCUSSION}

We found very low levels of communication and coordination among CARs in the Colombian Andes with respect to the conservation and research of Andean bears. Our analysis of spatial fit indicated that close to $70 \%$ of the ecological ties created by probable Andean bear movement between adjacent CARs were not matched with inter-institutional communication or coordination, suggesting little immediate capacity for collective action across these boundaries (Bodin and Crona 2009). Among general issues caused by the lack of communication and coordination, e.g., redundant efforts or lack of social learning, qualitative interview data also suggested several issues that were symptomatic of social-ecological mismatches such as incompatible datasets between neighboring CARs, a supposed lack of consideration of protected areas in neighboring CARs in reserve design and land acquisition, and the lack of institutional response to suspected Andean bear depredation events in jurisdictional border zones mentioned previously. The incompatibility of datasets prevents CARs from pooling their data to draw conclusions about the broader status of Andean bear populations in the Colombian Andes, while the latter two issues have consequences for the probability of successful Andean bear movement across jurisdictional boundaries. Conversely, members of the eastern cordillera inter-institutional agreement (which aligned perfectly with the central cordillera oriental ecoregion and contained the most social-ecological matches in the Andes) had the same methodology for assessing Andean bear occupancy, a shared protocol for responding to depredation events, and established communication channels for addressing issues at border zones (Hohbein et al. 2021). Thus, this voluntary collaborative agreement has allowed participants to address many issues of social-ecological fit in the central region of the eastern cordillera.

Although direct institutional ties between neighboring CARs were rare, entities of PNN as well as NGOs often served as intermediaries between otherwise disconnected CARs, bringing
Fig. 7. The inclusion of nongovernmental organizations and Colombia's National Natural Park Service brought most $(\mathrm{n}=$ $21 ; 81 \%$ ) of the autonomous regional corporations (corporaciones autonomas regionales [CARs]) into a single connected component. Cumulative weights of the intervening paths between CARs that did not directly communicate with one another (but did share correspondents) are provided; a higher weight suggests that information is less likely to travel from one CAR to the other. CARs connected by lines of any color are considered ecologically connected via probable movement of Andean bears (Tremarctos ornatus).

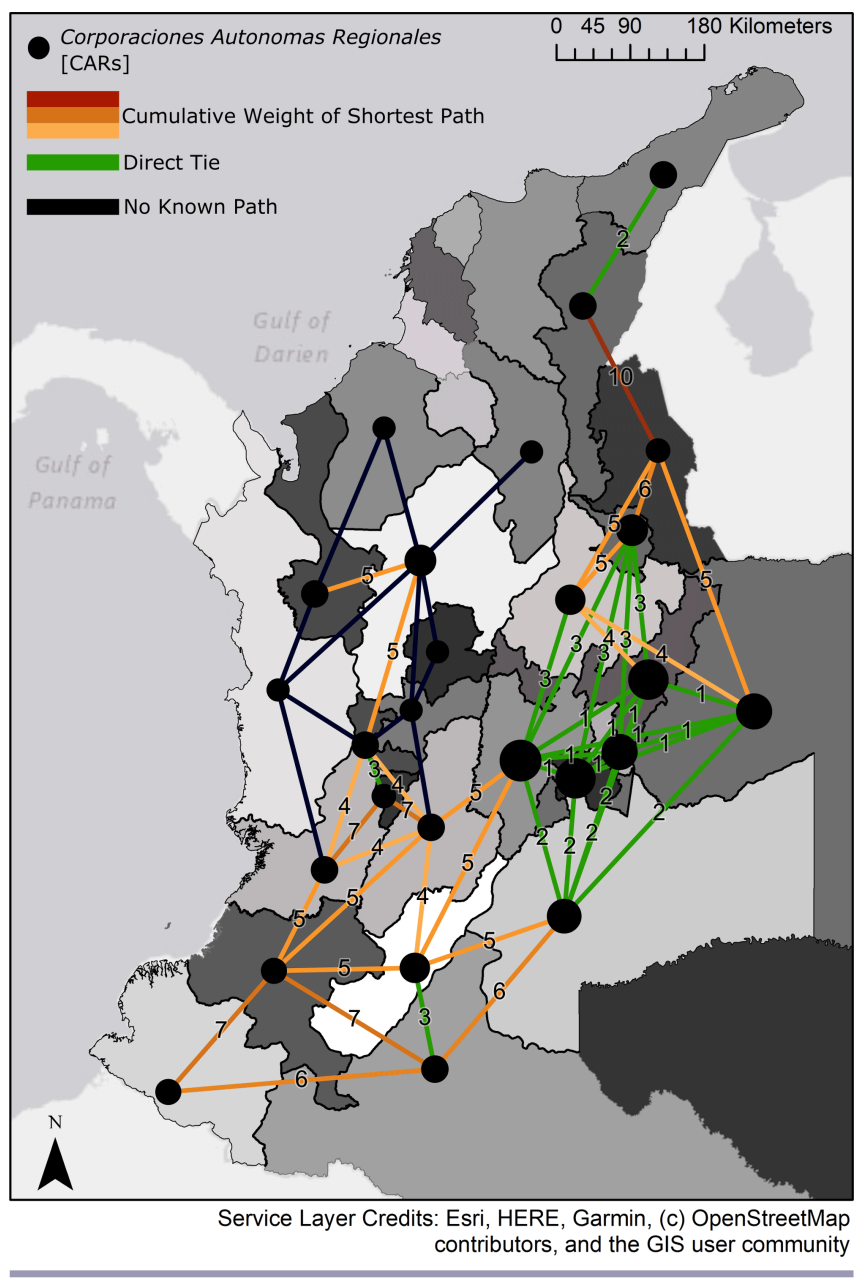

nearly all CARs working to conserve Andean bears across the Colombian Andes into a single connected component. This is significant because it demonstrates the existence of potential pathways through which information could travel to and from neighboring CARs. Stronger and more numerous pathways interlinking these CARs increase the likelihood that these entities will eventually communicate or even come to collaborate on conservation initiatives for the species. PNN entities had the highest average betweenness centrality scores of the three types of actors considered in this analysis (meaning that they most often appeared between otherwise disconnected actors), suggesting that they have great potential for distributing information to their 
correspondents and encouraging the development of institutional ties that would improve social-ecological fit for Andean bear conservation in the country (Bodin and Crona 2009). The degree to which they are leveraging this advantageous position in the network for such ends is currently unknown. Though PNN correspondents often spoke of the importance of coordinating their own efforts with the CARs, e.g., for the designation and management of buffer zones surroundings national natural parks, only one PNN correspondent we interviewed spoke of the importance or need for the CARs to coordinate their efforts with one another. Conversely, the lack of coordination among CARs was a common theme during interviews with Colombian NGO representatives; representatives described it as a challenge to the implementation of their Andean bear conservation programs. Several NGOs were actively working to facilitate communication between the CARs to remedy this. The degree to which the removal of NGOs from the conservation network impacted the extent to which CARs were interconnected (as observed with the change in WCIs) suggests that they too are strategically positioned for these efforts.

NGOs varied in their structural impacts on the institutional network (visible in Fig. 6). These different patterns in network structure that radiate from these NGOs dictate how information is likely to travel in the network and the bonds that could be created through mutual correspondents. For example, the two NGOs with the highest betweenness centrality scores, WCS and Fundación Wii, had drastically different network structures. WCS had stronger ties to other actors (indicative of more enduring communication channels), whereas Fundación Wii's immediate network was characterized by more weak ties (indicating more infrequent communications). WCS had a large-scale Andean bear conservation program characterized by longer term partnerships with local allies, notably including the national office of PNN, and a concerted effort to share monitoring and human-bear conflict mitigation strategies with interested CARs. Conversely, Fundación Wii operated primarily through comparatively shortterm contracts with the CARs to do various forms of community engagement and research and monitoring programs. Upon contract termination, little on-going communication remained. However, Fundación Wii continued to receive occasional phone calls from previous contacts at the CARs whenever further questions about the species arose. WCS, having stronger institutional ties, is better positioned to transfer complex knowledge to their correspondents, important for building a consistent monitoring strategy across the Andes. They are also more likely to be a catalyst for triadic closure (Granovetter 1973). Fundación Wii, through their weak ties, may be acting as a critical bridge across the network, allowing for greater dissemination of information between and among heterogeneous sub-groups (Granovetter 1973, Bodin and Crona 2009).

Overall, our results are consistent with those found by others who investigated the social-ecological fit achieved by self-organized networks. Specifically, collaborative ties were relatively sparse, and the network was characterized by more social-ecological mismatches than matches (Bergsten et al. 2014). We reach a similar conclusion as Guerrero et al. (2015) that although conservation actors can be successful in self-organizing and overcoming issues of fragmented management, the Andean bear conservation network would generally benefit from guidance in the targeting and formation of these inter-institutional ties. However, our approach of including non-jurisdictional entities into our analysis was critical in allowing us to identify which organizations might be best positioned for and most interested in providing such guidance.

\section{Limitations of this research}

Our institutional network excluded ties between actors that covered topics other than Andean bear conservation and research. Perhaps most notably, we did not include communication ties formed through GEF-SINAP, a Global Environmental Facility project aimed at enhancing the communication and coordination of regional and national protected area management in Colombia and executed by PNN (Global Environmental Facility 2021). Thus, some members of PNN, through GEF-SINAP, are directly facilitating communication among CARs. However, these communication channels are in support of protected area management, specifically, and involve correspondents at CARs distinct from those managing Andean bear conservation and research programs. For these reasons, these communication channels were not included in our analysis of social-ecological fit for Andean bear conservation. However, these alternative pathways represent important possible catalysts for the formation of new communication ties between CARs that could include the Andean bear conservation practitioners. We must further emphasize that CARs are large institutions, often with hundreds of employees working on numerous topics. We do not claim a complete understanding of the status of collaboration between CARs more generally. Our analysis includes the perspectives and networks of only those actors at the CARs responsible for designing, implementing, and managing programs for Andean bears.

Finally, many actors in the network named local NGOs, community groups, farmer's associations, and municipal town halls as allies in their Andean bear conservation and research efforts. Our inclusion criteria, which were guided by our desire to map horizontal social-ecological fit across Colombia, meant that these local-scale actors were not included in this analysis. By excluding these actors from our analysis, we do not mean to suggest these connections were unimportant; quite the contrary, these connections are critical to achieving vertical socialecological fit, e.g., between regional planning and local implementation. We simply did not have the time and resources available to investigate this other critical dimension of spatial fit for Andean bear conservation.

\section{CONCLUSION}

We examined the social-ecological fit of actors across the Colombian Andes working to conserve the Andean bear. We found that CARs, the primary entities responsible for implementing conservation policy in Colombia, rarely communicated directly with one another about their Andean bear conservation and research strategies, leading to many socialecological mismatches. Our qualitative data suggest that such mismatches create issues for comprehensive status assessments about Andean bears in the Colombian Andes and potentially exacerbate human-bear conflict at jurisdictional border zones. Limited communication among CARs (and therefore limited social learning) is unfortunate given that neighboring CARs likely face similar challenges regarding the conservation of this species 
and would have much to gain from sharing their experiences with one another.

CARs were more likely to communicate with entities of PNN and with NGOs about their Andean bear efforts. PNN entities had the highest average betweenness centrality scores in the network, but our qualitative interview data suggest they may not be using this advantageous position to foster inter-institutional coordination regarding Andean bear conservation and research efforts among the CARs with whom they correspond. Conversely, NGOs (several of whom were in an almost equal if not more advantageous position in the conservation network) seem to be more troubled by the lack of inter-institutional coordination among CARs for Andean bear conservation and were actively working to amend this situation. Two NGOs, WCS - Colombia and Fundación Wii, had the highest betweenness centrality scores of all 48 conservation actors in the network, suggesting that they, in particular, could help to coordinate the network in such a way so as to improve social-ecological fit for the conservation of the Andean bear in Colombia.

To our knowledge, this is the first empirical assessment of the impacts of non-jurisdictional actors on social-ecological fit among jurisdictional actors. Our data suggest that NGOs may be particularly helpful in stimulating cross-jurisdictional efforts because of the non-jurisdictional nature of their work and their propensity to be common allies among otherwise disconnected actors. Intentional and strategic leadership from conservation actors that find themselves at the nexus of many disconnected actors could be key to improving social-ecological fit.

Responses to this article can be read online at: https://www.ecologyandsociety.org/issues/responses. $\mathrm{php} / 12745$

\section{Acknowledgments:}

This research was supported by grants from The National Geographic Society (Grant \# EC-331r-18) and the International Association for Bear Research and Management. Further support was provided by several departments at the University of Georgia including Warnell School of Forestry and Natural Resources, the Center for Integrative Conservation Research, and the Graduate School. We would like to thank all those who graciously volunteered their time to participate in this study. We thank M. Guarnizo Pulido, V. Guarnizo Pulido, and D. Zambrano for serving as interpreters throughout the study. We thank J. Velásquez Runk, P. Dunne, and D. Markewitz for their thoughtful feedback on earlier versions of the manuscript. Finally, we thank two anonymous reviewers who provided constructive comments and suggestions that improved the manuscript.

\section{Data Availability:}

The datalcode that support the findings of this study are available on request from the corresponding author, RRH. None of the datal code are publicly available because they contain information that could compromise the privacy of research participants. Ethical approval for this research study was granted by the Institutional Review Board at the University of Georgia (\#STUDY00005270).

\section{LITERATURE CITED}

Alexander, S. M., D. Armitage, P. J. Carrington, and Ö. Bodin. 2017. Examining horizontal and vertical social ties to achieve social-ecological fit in an emerging marine reserve network. Aquatic Conservation: Marine and Freshwater Ecosystems 27:1209-1223. https://doi.org/10.1002/aqc. 2775

Armenteras, D., F. Gast, and H. Villareal. 2003. Andean forest fragmentation and the representativeness of protected natural areas in the eastern Andes, Colombia. Biological Conservation 113:245-256. https://doi.org/10.1016/S0006-3207(02)00359-2

Bax, V., and W. Francesconi. 2019. Conservation gaps and priorities in the Tropical Andes biodiversity hotspot: implications for the expansion of protected areas. Journal of Environmental Management 232:387-396. https://doi.org/10.1016/j.jenvman.2018.11.086

Bergsten, A., D. Galafassi, and Ö. Bodin. 2014. The problem of spatial fit in social-ecological systems: detecting mismatches between ecological connectivity and land management in an urban region. Ecology and Society 19(4):6. https://doi. org/10.5751/ES-06931-190406

Bernard, H. R. 2011. Interviewing: unstructured and semistructured. Pages 210-250 in Research methods in anthropology: qualitative and quantitative approaches. Rowman and Littlefield, Lanham, Maryland, USA.

Blackman, A., S. Hoffman, R. Morgenstern, and E. Topping. 2004. Assessment of Colombia's National Environmental System (SINA). Resources for the Future, Washington, D.C., USA.

Bodin, Ö. 2017. Collaborative environmental governance: achieving collective action in social-ecological systems. Science 357:eaan1114. https://doi.org/10.1126/science.aan1114

Bodin, Ö., and B. I. Crona. 2009. The role of social networks in natural resource governance: what relational patterns make a difference? Global Environmental Change 19:366-374. https:// doi.org/10.1016/j.gloenvcha.2009.05.002

Bodin, Ö., B. Crona, M. Thyresson, A. L. Golz, and M. Tengö. 2014. Conservation success as a function of good alignment of social and ecological structures and processes. Conservation Biology 28:1371-1379. https://doi.org/10.1111/cobi.12306

Bodin, Ö., A. Sandström, and B. Crona. 2017. Collaborative networks for effective ecosystem-based management: a set of working hypotheses. Policy Studies Journal 45:289-314. https:// doi.org/10.1111/psj.12146

Cumming, G. S., Ö. Bodin, H. Ernstson, and T. Elmqvist. 2010. Network analysis in conservation biogeography: challenges and opportunities. Diversity and Distributions 16:414-425. https:// doi.org/10.1111/j.1472-4642.2010.00651.x

Cumming, G. S., D. H. M. Cumming, and C. L. Redman. 2006. Scale mismatches in social-ecological systems: causes, consequences, and solutions. Ecology and Society 11(1):14. https://doi.org/10.5751/ES-01569-110114 
Davis, M. B., and R. G. Shaw. 2001. Range shifts and adaptive responses to quaternary climate change. Science 292:673-679. https://doi.org/10.1126/science.292.5517.673

de Lange, E., E. Milner-Gulland, and A. Keane. 2019. Improving environmental interventions by understanding information flows. Trends in Ecology \& Evolution 34:1034-1047. https://doi. org/10.1016/j.tree.2019.06.007

Dressel, S., G. Ericsson, M. Johansson, C. Kalén, S. Pfeffer, and C. Sandström. 2020. Evaluating the outcomes of collaborative wildlife governance: the role of social-ecological system context and collaboration dynamics. Land Use Policy 99:105028. https:// doi.org/10.1016/j.landusepol.2020.105028

Dressel, S., G. Ericsson, and C. Sandström. 2018. Mapping socialecological systems to understand the challenges underlying wildlife management. Environmental Science \& Policy 84:105-112. https://doi.org/10.1016/j.envsci.2018.03.007

Dupar, M. K., and N. Badenoch. 2002. Environment, livelihoods, and local institutions: decentralization in mainland Southeast Asia. World Resources Institute, Washington, D.C., USA. [online] URKL: https://dlc.dlib.indiana.edu/dlc/bitstream/ handle/10535/3714/decentralization msea.pdf

Ekstrom, J. A., and O. R. Young. 2009. Evaluating functional fit between a set of institutions and an ecosystem. Ecology and Society 14(2):16. https://doi.org/10.5751/ES-02930-140216

Enqvist, J. P., M. Tengö, and Ö. Bodin. 2020. Are bottom-up approaches good for promoting social-ecological fit in urban landscapes? Ambio 49:49-61. https://doi.org/10.1007/s13280-019-01163-4

Epstein, G., J. Pittman, S. M. Alexander, S. Berdej, T. Dyck, U. Kreitmair, K. J. Rathwell, S. Villamayor-Tomas, J. Vogt, and D. Armitage. 2015. Institutional fit and the sustainability of socialecological systems. Current Opinion in Environmental Sustainability 14:34-40. https://doi.org/10.1016/j.cosust.2015.03.005

Etter, A., C. McAlpine, and H. Possingham. 2008. Historical patterns and drivers of landscape change in Colombia since 1500: a regionalized spatial approach. Annals of the Association of American Geographers 98:2-23. https://doi.org/10.1080/000456$\underline{00701733911}$

Etter, A., and W. van Wyngaarden. 2000. Patterns of landscape transformation in Colombia, with emphasis in the Andean region. Ambio 29:432-439. https://doi.org/10.1579/0044-7447-29.7.432

Falconi, N., T. K. Fuller, S. Destefano, and J. F. Organ. 2020. An open-access occurrence database for Andean bears in Peru. Ursus 2020:1-6. https://doi.org/10.2192/URSUS-D-19-00012.1

Folke, C., L. Pritchard Jr, F. Berkes, J. Colding, and U. Svedin. 2007. The problem of fit between ecosystems and institutions: ten years later. Ecology and Society 12(1):30. https://doi.org/10.5751/ ES-02064-120130

Fuhse, J., and S. Mützel. 2011. Tackling connections, structure, and meaning in networks: quantitative and qualitative methods in sociological network research. Quality \& Quantity 45:1067-1089. https://doi.org/10.1007/s11135-011-9492-3
García-Rangel, S. 2012. Andean bear Tremarctos ornatus natural history and conservation. Mammal Review 42:85-119. https://doi. org/10.1111/j.1365-2907.2011.00207.x

Garshelis, D. L. 2011. Andean bear density and abundance estimates-How reliable and useful are they? Ursus 22:47-64. https://doi.org/10.2192/URSUS-D-10-00030.1

Global Environmental Facility. 2021. Consolidation of the National System of Protected Areas (SINAP) at national and regional levels. Global Environmental Facility. [online] URL: https://www.thegef.org/project/consolidation-national-system-protectedareassinap-national-and-regional-levels

Goldstein, I., S. Paisley, R. Wallace, J. P. Jorgenson, F. Cuesta, and A. Castellanos. 2006. Andean bear-livestock conflicts: a review. Ursus 17:8-15. https://doi.org/10.2192/1537-6176(2006) 17[8:ABCAR]2.0.CO;2

Granovetter, M. S. 1973. The strength of weak ties. American Journal of Sociology 78:1360-1380. https://doi.org/10.1086/225469

Guerrero, A. M., M. Barnes, Ö. Bodin, I. Chadès, K. J. Davis, M. S. Iftekhar, C. Morgans, and K. A. Wilson. 2020. Key considerations and challenges in the application of socialnetwork research for environmental decision making. Conservation Biology 34:733-742. https://doi.org/10.1111/ cobi.13461

Guerrero, A. M., Ö. Bodin, R. R. McAllister, and K. A. Wilson. 2015. Achieving social-ecological fit through bottom-up collaborative governance: an empirical investigation. Ecology and Society 20(4):41. https://doi.org/10.5751/ES-08035-200441

Gutiérrez-Gómez, L. 2017. Mining in Colombia: tracing the harm of neoliberal policies and practices. Pages 85-113 in D. Rodríguez Goyes, H. Mol, A. Brisman, and N. South, editors. Environmental crime in Latin America. Palgrave Macmillan, London, UK. https://doi.org/10.1057/978-1-137-55705-6_5

Hahn, T., P. Olsson, C. Folke, and K. Johansson. 2006. Trustbuilding, knowledge generation and organizational innovations: the role of a bridging organization for adaptive comanagement of a wetland landscape around Kristianstad, Sweden. Human Ecology 34:573-592. https://doi.org/10.1007/s10745-006-9035-Z

Hohbein, R. R., and N. P. Nibbelink. 2021. Omnidirectional connectivity for the Andean bear (Tremarctos ornatus) across the Colombian Andes. Landscape Ecology 36:3169-3185. https:// doi.org/10.1007/s10980-021-01299-3

Hohbein, R. R., N. P. Nibbelink, and R. J. Cooper. 2021. Impacts of decentralized environmental governance on Andean bear conservation in Colombia. Environmental Management. https:// doi.org/10.1007/s00267-021-01532-4

Janssen, M. A., Ö. Bodin, J. M. Anderies, T. Elmqvist, H. Ernstson, R. R. J. McAllister, P. Olsson, and P. Ryan. 2006. Toward a network perspective of the study of resilience in socialecological systems. Ecology and Society 11(1):15. https://doi. org/10.5751/ES-01462-110115

Jenks, G. F. 1967. The data model concept in statistical mapping. International Yearbook of Cartography 7:186-190. 
Kattan, G., O. L. Hernández, I. Goldstein, V. Rojas, O. Murillo, C. Gómez, H. Restrepo, and F. Cuesta. 2004. Range fragmentation in the spectacled bear Tremarctos ornatus in the northern Andes. Oryx 38:155-163. https://doi.org/10.1017/ $\underline{\text { S0030605304000298 }}$

Koen, E. L., J. Bowman, C. Sadowski, and A. A. Walpole. 2014. Landscape connectivity for wildlife: development and validation of multispecies linkage maps. Methods in Ecology and Evolution 5:626-633. https://doi.org/10.1111/2041-210X.12197

Littlefield, C. E., M. Krosby, J. L. Michalak, and J. J. Lawler. 2019. Connectivity for species on the move: supporting climatedriven range shifts. Frontiers in Ecology and the Environment 17:270-278. https://doi.org/10.1002/fee.2043

Mantilla Valbuena, S. 2012. Economía y conflicto armado en Colombia: los efectos de la globalización en la transformación de la guerra. Latinoamérica Revista de estudios Latinoamericanos 55:35-73. https://doi.org/10.22201/cialc. 24486914e.2012.55.56495

Marshall, D. J., and L. Staeheli. 2015. Mapping civil society with social network analysis: methodological possibilities and limitations. Geoforum 61:56-66. https://doi.org/10.1016/j. geoforum.2015.02.015

Mbaru, E. K., and M. L. Barnes. 2017. Key players in conservation diffusion: using social network analysis to identify critical injection points. Biological Conservation 210:222-232. https://doi.org/10.1016/j.biocon.2017.03.031

McRae, B. H., B. G. Dickson, T. H. Keitt, and V. B. Shah. 2008. Using circuit theory to model connectivity in ecology, evolution, and conservation. Ecology 89:2712-2724. https://doi.org/10.1890/07-1861.1

Mittermeier, R. A., N. Myers, C. G. Mittermeier, editors. 1999. Hotspots: Earth's biologically richest and most endangered terrestrial ecoregions. CEMEX, S. A., Mexico City, Mexico.

Negret, P. J., J. Allan, A. Braczkowski, M. Maron, J. E. M. Watson. 2017. Need for conservation planning in postconflict Colombia. Conservation Biology 31:499-500. https://doi.org/10.1111/ cobi. 12935

Olsson, P., C. Folke, V. Galaz, T. Hahn, and L. Schultz. 2007. Enhancing the fit through adaptive co-management: creating and maintaining bridging functions for matching scales in the Kristianstads Vattenrike Biosphere Reserve, Sweden. Ecology and Society 12(1):28. https://doi.org/10.5751/ES-01976-120128

Orejuela, J., and J. Jorgenson. 1999. Status and management of the spectacled bear in Colombia. Pages 168-179 in C. Servheen, S. Herrero, and B. Peyton, compilers. Bears: status survey and conservation action plan. International Union for the Conservation of Nature, Gland, Switzerland.

Parra-Romero, Á., R. Galindo-Tarazona, J. F. González-Maya, and I. M. Vela-Vargas. 2019. Not eating alone: Andean bear time patterns and potential social scavenging behaviors. Therya 10:49-53. https://doi.org/10.12933/therya-19-625

Pelosi, C., M. Goulard, and G. Balent. 2010. The spatial scale mismatch between ecological processes and agricultural management: do difficulties come from underlying theoretical frameworks? Agriculture, Ecosystems \& Environment 139:455-462. https://doi.org/10.1016/j.agee.2010.09.004
Pening Gaviria, J. 2003. Evaluación del proceso de descentralización en Colombia [Evaluating the decentralization process in Colombia]. Economía y Desarrollo 2:123-149.

Peyton, B. 1980. Ecology, distribution, and food habits of spectacled bears, Tremarctos ornatus, in Peru. Journal of Mammalogy 61:639-652. https://doi.org/10.2307/1380309

Peyton, B. 1999. Spectacled bear conservation action plan. Pages 157-198 in C. Servheen, S. Herrero, and B. Peyton, compilers. Bears: status survey and conservation action plan. International Union for the Conservation of Nature, Gland, Switzerland.

Peyton, B., E. Yerena, D. I. Rumiz, J. Jorgenson, and J. Orejuela. 1998. Status of wild Andean bears and policies for their management. Ursus 87-100.

Pittman, J., and D. Armitage. 2017. How does network governance affect social-ecological fit across the land-sea interface? An empirical assessment from the Lesser Antilles. Ecology and Society 22(4):5. https://doi.org/10.5751/es-09593-220405

Prell, C., K. Hubacek, and M. Reed. 2009. Stakeholder analysis and social network analysis in natural resource management. Society and Natural Resources 22:501-518. https://doi. org/10.1080/08941920802199202

Riggs, R. A., J. D. Langston, and S. Phann. 2020. Actor network analysis to leverage improvements in conservation and development outcomes in Cambodia. Ecology and Society 25 (4):28. https://doi.org/10.5751/es-11854-250428

Rodríguez Becerra, M. 2009. ¿Hacer más verde al estado colombiano? [Greening the Colombian state?] Revista de Estudios Sociales 32:18-33. https://doi.org/10.7440/res32.2009.01

Saldaña, J. 2016. The coding manual for qualitative researchers. SAGE, Los Angeles, California, USA.

Sayles, J. S., and J. A. Baggio. 2017. Social-ecological network analysis of scale mismatches in estuary watershed restoration. Proceedings of the National Academy of Sciences 114:E1776E1785. https://doi.org/10.1073/pnas.1604405114

Sayles, J. S., M. M. Garcia, M. Hamilton, S. M. Alexander, J. A. Baggio, A. P. Fischer, K. Ingold, G. R. Meredith, and J. Pittman. 2019. Social-ecological network analysis for sustainability sciences: a systematic review and innovative research agenda for the future. Environmental Research Letters 14:093003. https:// doi.org/10.1088/1748-9326/ab2619

Scott, J. 1988. Social network analysis. Sociology 22:109-127. https://doi.org/10.1177/0038038588022001007

Taylor, P. D., L. Fahrig, K. Henein, and G. Merriam. 1993. Connectivity is a vital element of landscape structure. Oikos 68:571-573. https://doi.org/10.2307/3544927

Velez-Liendo, X., and S. García-Rangel. 2017. Tremarctos ornatus. The IUCN Red List of Threatened Species, Cambridge, UK. [online] URL: https://www.iucnredlist.org/species/22066/123792952

Vélez-Torres, I., and G. Ruiz-Torres. 2015. Extractivismo neoliberal minero y conflictos socio-ambientales en Perú y Colombia. Ambiente y Sostenibilidad 5:3-15. 
Yerena, E. 1998. Protected areas for the Andean bear in South America. Ursus 10:101-106.

Zukowski, B., and A. Ormsby. 2016. Andean bear livestock depredation and community perceptions in northern Ecuador. Human Dimensions of Wildlife 21:111-126. https://doi. org/10.1080/10871209.2015.1126871 